\title{
Gelling Behavior of Plant Proteins and Polysaccharides in Food Systems
}

\author{
Florence O. Uruakpa \\ Department of Applied Health Sciences, Indiana State University, Terre Haute, IN 47809, USA
}

Received: October 31, 2011 / Published: May 20, 2012.

\begin{abstract}
Biological macromolecules, such as proteins and polysaccharides, are widely used in food systems because their interactions impart a desirable texture to food products. Plant proteins interact with food components via protein-protein and protein-polysaccharide associations, and the formation of a matrix, which can entrap other food components such as water, lipids and flavors. These networks provide structural integrity to food products and can serve as important functional ingredients in processed foods. Intermolecular interactions of typical polysaccharides result either in simple associations or in the form of a double or triple helix. The linear double helical segments may then interact to form a super junction and a three-dimensional gel network. The formation of these structural networks takes place during processing and involves the transformation from a liquid or viscous sol into a solid material with elastic properties. Interests in the behavior of mixed gels center on the prospects of enhanced flexibility in their mechanical and structural properties compared to those of pure gels. Findings on molecular interactions between plant proteins (e.g., soy, canola and pea proteins) and polysaccharides (e.g., guar gum, carrageenan, and pectin) allow for the modification of physical and textural characteristics of mixed biopolymers to meet desired functional property.
\end{abstract}

Key words: Molecular interactions, plant proteins and polysaccharides, gelling macromolecules.

\section{Introduction}

Protein functionality in food systems may be affected by other components in that system. Understanding the interactions between components in food systems is a prerequisite for the incorporation of plant proteins (e.g., soy, canola and wheat proteins) into conventional foods or the development of new food products. Industrial significance of interactions between proteins and polysaccharides for protein recovery, protein stabilization and food texture modification has been documented [1-3]. The type of association does not necessarily determine the contribution to the functional properties of the food. For example, thermally stable protein gels have been produced through electrostatic interactions between sodium alginate and sodium caseinate [4]. However, studies with canola protein isolate (CPI) revealed that

Corresponding author: Florence O. Uruakpa, Ph.D., assistant professor, research fields: food protein chemistry and functional foods. E-mail: ojiugou@yahoo.com. the addition of low concentrations of guar gum improved protein gel properties [5]; but not when sodium alginate or methylcellulose was included [6].

Gelation is an important functional property of globular proteins (e.g., soy proteins) commonly used in the food industry. However, studies [7-10] showed that several factors influence the nature of the protein gel formed. These include environmental conditions (such as $\mathrm{pH}$, ionic strength and mineral content), protein properties/composition (e.g., hydrophobicity, level of sulfhydryl groups, charge potential), electrolytes, phytochemicals (phenolic and phytic acids), processing conditions (e.g., heating and cooling rates), extent of denaturation, and concentration. The behavior of protein-polysaccharide mixtures has been the subject of many investigations. As many as 80 protein-polysaccharide-water ternary systems have been described by Tolstoguzov [3, 4, 11]. Results were obtained for a mixture of casein micelles with guar gum and a segregative phase 
separation phenomenon between the micellar casein and guar gum was reported [12]. Similarly, the ability to improve the surface and emulsifying characteristics of CPI networks through the addition of a small amount of $\kappa$-carragenan or guar gum has been demonstrated [5]. However, this improvement was not simply due to the incompatibility of the biopolymers as similar interaction data for methyl cellulose did not produce the same gelation properties [6]. Thus, great potential remains for mixing polysaccharides with globular proteins.

The control or manipulation of protein-polysaccharide interactions is a major factor in the development of novel foods [13]. The understanding of factors that influence structural characteristics of plant proteins in the presence of polysaccharides can provide useful information on the utilization of potential functional ingredients (e.g., canola and pea proteins) to improve the quality of food products. This review examines the behavior of plant proteins in multicomponent food systems.

\section{Gelling Patterns of Proteins and Polysaccharides}

\subsection{Gelling of Globular Proteins}

Proteins are industrially important because of their gel-forming ability [14] and surface activity [15]. Network formation is vital to the development of texture within foods. It provides structural matrices for holding moisture, flavors, sugars and other food ingredients, and it lends to the stabilization of dispersed phases [14]. Proteins capable of forming network are classified as either fibrous or globular. Gelation is defined as the aggregation of protein (usually denatured) into an ordered matrix in which there is a balance between protein-protein and protein-solvent interactions, and is maintained by a balance of attractive and repulsive forces [16]. Since proteins are generally stable in aqueous solution, denaturation/destabilization is a prerequisite for gelation. For instance, canola protein forms a gel at a denaturation temperature $\left(\mathrm{T}_{\mathrm{d}}\right) \geq 86{ }^{\circ} \mathrm{C}$ [5]. Protein gelation refers to transformation of a protein from the sol (fluid molecular dispersion) state to a gel-like state [17]. Denaturation/destabilization is usually induced by thermal treatment while other techniques such as denaturant- $[18,19]$ or pressure-induction $[20,21]$ can also be employed. Enzymatic crosslinking [22, 23] and treatment with divalent cations under appropriate conditions [24] would be other ways to form protein gels. All these agents induce (by denaturation) the formation of structural networks.

During thermogelation, the protein in a sol state is first transformed into a progel state (a viscous liquid state in which some degree of protein polymerization has already occurred) following denaturation. Globular proteins from milk (casein), egg white (ovalbumin), soybean (7S, 11S globulins) and muscle (myosin) can also form gels through various intermolecular forces when denatured. In the gelation of a globular protein [25], the protein sol is converted to a high viscosity progel by heat which sets to a gel of higher viscosity upon cooling (Fig. 1). The initial heating causes an irreversible dissociation of the globulin polypeptides [26]. Once the sol has been converted to a progel, it can only be converted to a gel or metasol. When the progel or gel is excessively heated $\left(125^{\circ} \mathrm{C}\right)$, a metasol is formed, which does not form a gel on cooling. A metasol is also obtained by the action of chemical denaturants (e.g., 6 M Urea, sulfite, mercaptoethanol), which causes the chemical modification of functional groups. The most common way to produce protein gels is with heat treatment hence this review centers on thermally-induced gelation.

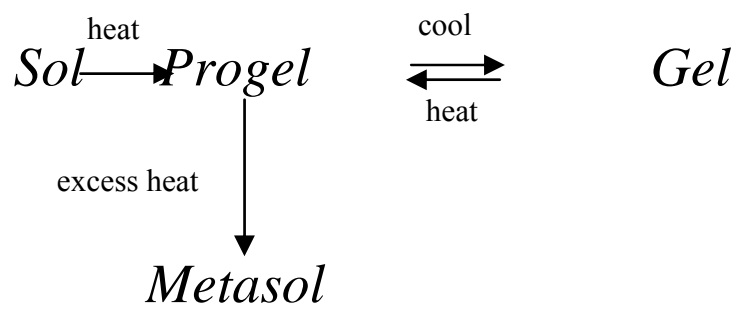

Fig. 1 Schematic representation of globular protein gelation [25]. 
2.1.1 Mechanisms for Network Formation by Globular Protein

Gelation process is carried out in several stages including conformational changes of protein molecules, their aggregation and formation of a 3-D gel network from interacting aggregates. The first and critical step in thermogelation of globular protein is denaturation (at least partially). Ferry [27] proposed this two-step process of globular protein gelation:

Native state $\rightarrow$ Denatured state $\rightarrow$ Aggregation

The picture outlined in Ferry's review is that on heat-induced denaturation, a protein completely unfolds, and then intermolecular interactions lead to the formation of a fine-meshed "macromolecular" gel. This principle is still quite appropriate for gelatin [28] and for some chemically denatured globular proteins, but for heat-set globular proteins the picture is different. According to Ferry's theory, the type of network formed depends on the relative rates of the two steps. More recent study has shown that this theory was not entirely accurate. Departure from Ferry's view resulted after evidence suggested that interaction of partially unfolded, rather than fully extended, polypeptide chains were responsible for network formation in globular proteins [29]. Problems (i.e., conclusions that protein gelation involves a two-step process and complete unfolding of a protein) with Ferry's theory were particularly noticeable in electron microscopy studies where the widths of the protein strands in the networks were actually measured.

As a result, Ferry's theory has been replaced with the "corpuscular theory", a three-step mechanism proposed for protein network formation [29]. In the corpuscular theory, the associating strands in protein networks are not polypeptide chains but a linkage of spherical bead-like structures. The following steps (Fig. 2) describe the formation and interaction of these beads:

Reports on globular protein gelation made valuable contributions to food texture development [14, 30]. For instance, it is known that in simple heat-induced denaturation, the protein size and shape is only mildly perturbed. Some of the hydrophobic groups, which at ambient temperatures remain buried in the protein core, become exposed above some minimum unfolding or denaturation temperature, $\mathrm{T}_{\mathrm{u}}$ (Here, this value corresponding to the onset of denaturation determined from a differential scanning calorimetry (DSC) endotherm, was distinguished from $T_{m}$, the temperature of maximum heat flow from a DSC). This effect leads to aggregation to form either fine stranded networks or amorphous particulate structures of a "physical gel" [31]. Globular proteins partially unfold to expose internal hydrophobic regions on heating. Therefore, heat-induced gelation is considered to achieve mainly through hydrophobic interactions among proteins [32].

Proteins are not totally unfolded when heated; a loss of $\alpha$-helix fraction and an increase in $\beta$-sheet are usually observed by circular dichroism (CD), infrared (IR) or nuclear magnetic resonance (NMR) spectroscopy [14, 33, 34]. Bouraoui et al. [35] conducted the first Raman spectroscopic analysis on structural changes in fish muscle protein, suggesting decreasing $\alpha$-helical fraction and increasing $\beta$-sheet fraction during gelation. If the secondary structures are totally lost, proteins behave as random coils and the gel-forming ability is lost [36]. Thus, an intermolecular $\beta$-sheet formation seems to be involved in protein aggregate formation [14]. Disulfide bridging (not all globular proteins contain disulfide crosslinks) is involved at $\mathrm{pH}$ values above 7.0 [37]. At alkaline $\mathrm{pH}$, increase in repulsive charges causes proteins to unfold; and for globular proteins containing

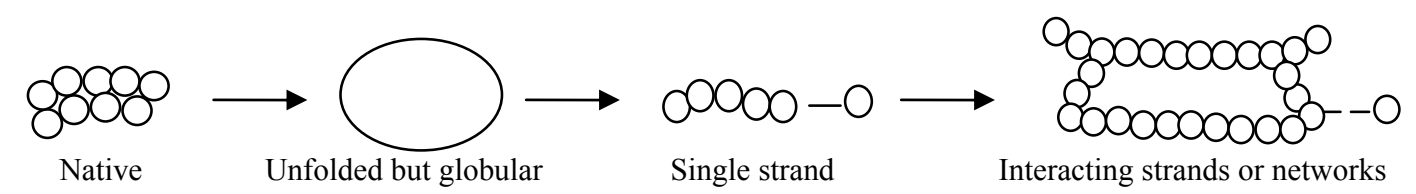

Fig. 2 Schematic representation of the corpuscular theory. 
disulfide bonds, the structural unfolding results to disulfide bridging. For example, $\beta$-lactoglobulin which has two disulfide bonds, is characterized by a tighter, less elastic conformation at acidic $\mathrm{pH}$ and a highly flexible, more hydrophobic molecule at $\mathrm{pH}$ values above 7.5 [38]. Gelling mechanisms are mainly controlled by the balance between attractive hydrophobic interactions and repulsive electrostatic interactions.

\subsection{Gelation Mechanisms of Polysaccharides}

As a general rule, regular linear segments of polysaccharide molecules are in the form of a helix. Intermolecular interactions result either in simple associations or in the form of a double (in some cases, a triple) helix (Fig. 3). The relatively stiff, linear double helical segments may then interact (pack together) to form a super junction and the three-dimensional gel network [39]. Typical gelling polysaccharides include $\kappa$ - and $\mathrm{t}$-carrageenans, locust bean gum, alginate, pectin, agarose and xanthan gum. Gelation mechanisms of typical polysaccharides can be divided into three types according to the nature of the junction zones: ribbon junctions, multiple helices and micelle junctions. The term junction zone is used to describe the crosslink because each crosslink involves aggregates of ordered molecular chains like helices. Junction zones between molecules and particles must be of limited size, and are segment interactions.

\subsubsection{Micelle Junction}

The gelling association between two different polysaccharides which usually cannot form gels as individuals is termed micelle junction [40]. For example, polysaccharide pairs: xanthan-galactomannan and agarose-galactomannan mixtures will follow the micelle junction gelation mechanism. Xanthan gum and galactomannan will react to form a gel with a very elastic, resilient texture and very high rupture strength. The gels are thermally reversible, and show sharp melting and setting behaviour over a narrow temperature range.

\subsubsection{Ribbon Junction}

Alginates and low methoxy pectin follow the ribbon junction gelation mechanism. This type of interaction involves simple ionic bridging of two carboxyl groups on adjacent polymer chains with calcium ions. Alginates (from brown seaweed) have linear polyuronic backbone with three types of block structure namely: poly- $\beta$-D-mannuronic acid $(\mathrm{M})$, poly- $\alpha$-L-guluronic acid $(\mathrm{G})$, and mixed (MG) block containing both uronic acids. It has been suggested that alginate gels are formed by ionic bridging of two carboxyl groups on adjacent polymer chains with

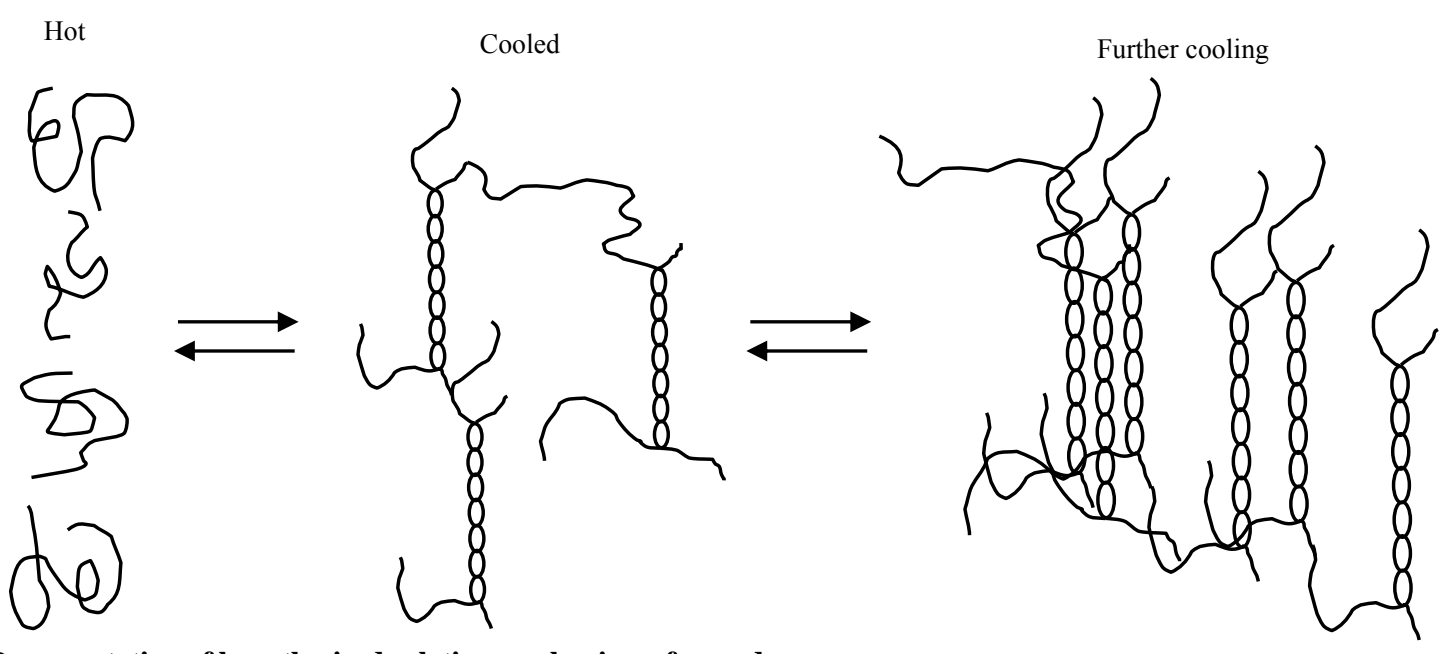

Fig. 3 Representation of hypothesized gelation mechanism of $\boldsymbol{k}$ - and $\mathrm{t}$-carrageenans.

The macromolecules are in coiled state under hot condition. As the dispersion cools, the molecules nest together in double helical structures. When cooled further, the double helices intertwine in the presence of calcium or potassium ions. Adapted from Whistler and BeMiller [39]. 
calcium ions. This takes place between guluronic acid chain segments. From circular dichroism and conformation studies done on isolated $\mathrm{M}$ and $\mathrm{G}$ segments, large transitions were observed for polyguluronic blocks and insignificant changes for the polymannuronic blocks. The "egg box" association is considered to involve cooperative binding of $\mathrm{Ca}^{2+}$ ions between aligned polyguluronic ribbons [40]. Oakenfull [41] revealed that alginate gels are not thermoreversible. Pectin (partial methyl ester of 1,4-linked poly- $\alpha$-D-galacturonic acid) can form two types of gels depending on their degree of esterification [42]. Low methoxy pectin is similar to alginate in gelling ability, and requires $\mathrm{Ca}^{2+}$ ion to form a gel network.

\subsubsection{Multiple Helices}

Associations between chains where two or more chains interact in a certain helical direction are termed multiple helices. Polysaccharides that form junction zones by this mechanism are carrageenans, agarose and amylose. Carrageenans are alternating copolymers of 1,3-linked $\beta$-D-galactose and 1,4-linked 3,6 anhydro- $\alpha$-D-galactose with varying amounts of sulfate ester. These copolymers contribute to the helical junction formation. Double helical conformation was characterized in solid state by X-ray fiber diffraction [40] as a threefold right-handed double helix. The forces involved in the formation of helices are mainly hydrogen bonds.

\section{Interactions in Multicomponent Systems}

\subsection{Salt Influences on Network Association}

The influence of solvent components, such as salt, on protein network properties can be by either direct interaction with the protein, indirect interaction through modification of the solvent environment or a combination of both [43]. Stabilizing or non-chaotropic salts (e.g., $\mathrm{NaCl}$ ) at moderate to high salt concentrations tend to promote hydrophobic interactions between protein molecules, thereby impeding network formation [44, 45]. On the other hand, chaotropic salts (e.g., $\mathrm{CaCl}_{2}$ ) tend to promote the formation of well cross-linked networks [44, 45].

For some proteins (e.g., ovalbumin), divalent cations contribute to network structure through the formation of salt bridges [46]. However, the amount of divalent cation and the type of anion associated with the cation are critical to optimizing this contribution $[7,46]$. For example, sodium salts, which promoted protein stability, had adverse effect on gelation [44]. Similarly, studies with ovalbumin and vicilin showed that higher $\mathrm{CaCl}_{2}$ levels resulted in increased vicilin network solubility and promoted ovalbumin aggregation [47].

\subsection{Molecular Interactions and Forces Responsible for Network Formation}

The interactions involved in network formation of proteins are primarily electrostatic interactions, hydrogen bonds and hydrophobic interactions. The relative contributions of these forces vary with the type of protein, heating conditions, the extent of denatureation, and environmental conditions. Disulfide bonds contribute more to networks formed from ovalbumin than those formed from plant proteins [44]. The study by Arntfield et al. [10] supported disulfide bond involvement in ovalbumin networks but not in vicilin networks. Although disulfide bonds may contribute to the elasticity and strength of a protein network, non-covalent forces are critical to initial network formation. Studies have shown that hydrophobic and electrostatic interactions, and disulfide bonds were responsible for the formation of canola protein gel networks $[44,48]$.

The report of McClements [49] showed that attractive or repulsive interactions between proteins and polysaccharides may serve to create microstructures that give foods new textural and sensory characteristics. Attractive electrostatic interactions at interface could produce emulsions with enhanced stability under environmental disturbances. 
A balance between the charge repulsion and the potential for interaction, mainly through hydrogen bonds and hydrophobic interactions, is critical to the attainment of network properties [7, 45]. Excessive attractive forces or insufficient charge repulsion results in aggregation rather than network formation. If proteins of opposite charge are present during network formation, as in the case with egg proteins ovalbumin and lysozyme, charge repulsion is low. While the strength of the network formed by this combination is increased compared to ovalbumin alone, the crosslinking within the structure is reduced [50].

Studies indicate that various molecular and thermodynamic factors could be manipulated to optimize the effectiveness of covalent and electrostatic complexes in the stabilization of interfaces, gels and emulsions. Dickinson [51] stated that Maillard-type protein-polysaccharide conjugates have excellent emulsifying and steric stabilizing properties, mainly under conditions where protein solubility is poor. Charged polysaccharides form soluble complexes or coacervates with proteins depending on $\mathrm{pH}$, ionic strength, and biopolymer charge distribution. The structure and stabilizing properties of the mixed protein-polysaccharide layer depends on the sequence of adsorption of the biopolymers to the interface. There is potential application for interfacial protein-polysaccharide complexes as delivery media for nutrient encapsulation and in the protection of adsorbed proteins and emulsified lipids against enzymatic breakdown during digestion. In a study on the rheological properties of complex coacervates formed by BSA/ $\kappa$-carrageenan, BSA/gum Arabic and BSA/pectin, Lee [52] found that the self-aggregation pattern of proteins may have marked influence on the final gel properties of protein-polysaccharide complexes. The data suggest that higher storage moduli for all protein-polysaccharide coacervates formed strong interconnected gel-like structure.

Another report [53] on pea protein- $\kappa$-carrageenan gel revealed the formation of pea protein aggregates network in the presence of $\kappa$-carrageenan with gelling behavior governed by continuous protein-enriched phase. Rheological and microstructural evaluation of mixed gels showed that the size of pea protein aggregates was larger at slower cooling rate but became smaller as cooling rate increased. Data indicated that the gelation mechanism of the mixed gel was controlled by the gelling behavior of the gum, $\kappa$-carrageenan [54]. A comprehensive review by Dickinson [55] compared the features of particle-stabilized droplets with those of conventional protein-stabilized emulsions. It revealed that particle-stabilized emulsions have different properties from protein-stabilized emulsions. A good understanding of these interactions would help to predict the optimum conditions and outcomes in multicomponent food systems.

\section{Role of Protein-Polysaccharide Interaction in Gel Formation: Some Insights in Commercial Canola Protein-Hydrocolloid Gelling Systems}

The gelation mechanisms and characteristics of soy proteins and other related plant proteins in food systems have been extensively studied, whereas information in the gelation of canola protein when used alone or in mixed form is limited. Proteins and polysaccharides contribute to the structure and stability of foods through their interactions. Gelling biopolymer dispersion is one where reactive macromolecules become progressively more crosslinked and aggregated as physical and/or chemical interactions occur. Interactions between proteins and polysaccharides may result in complex formation, homogeneous solutions and incompatibility [56]. Studies on protein-polysaccharide interactions showed that under some conditions, these interactions can result in improved gelation [11, 57] and emulsification properties [58]. Improvements in gelation properties of $\mathrm{CPI}$ at high $\mathrm{pH}$ have been shown by the addition of low concentration of guar 
gum and $\kappa$-canageenan [5], but not when methyl cellulose or locust bean gum were included. The gelation properties of these protein-polysaccharide mixtures were shown to be dependent on $\mathrm{pH}$ and salt concentration. Incompatibility of macromolecules, self-association and interbiopolymer complexing contribute to synergistic and antagonistic effects of food formulation [59].

Canola is the name adopted by the rapeseed industry in Canada in 1978 to identify rapeseed cultivars which are genetically low in both erucic acid and glucosinolates [60]. Interest in rapeseed as a protein source materialized in the sixties when it became generally appreciated that the essential amino acid composition of rapeseed protein compared favorably with that of soybean and the FAO/WHO protein reference pattern [61]; which was supported by the findings of Klockeman et al. [62]. However, the presence of antinutritional factors (e.g., glucosinolates, phytic acid, phenolic compounds) in canola protein limits the possibility of using this protein as a food ingredient [63]. Canola is widely grown, particularly in Canada, because it is a rich source of high quality edible oil [64]. The resulting meal after oil extraction contains about $35 \%-40 \%$ protein with a good balance of essential amino acids [62, 65] and a high protein efficiency ratio [66]. Canola meal finds use as an animal feed ingredient; however, the potential use of canola protein as a human food ingredient is being explored currently by some commercial food industries (e.g., Burcon NutraScience Corporation, Archer Daniels Midland Company).

The isoelectric point (IEP) of CPI was reported as pH 6.8-7.2 [67]. Since CPI gel is less elastic when compared to those of egg albumin [44], it is hypothesized that the addition of polysaccharides will enhance its gel strength. Benchmark research [5] was conducted on commercial (BMW Canola, Winnipeg, Canada) canola protein isolate mixed with hydrocolloids ( $\kappa$-carrageenan, guar gum). Prior to dynamic rheological testing, a denaturation temperature $\left(\mathrm{T}_{\mathrm{d}}\right)$ of $86{ }^{\circ} \mathrm{C}$ was determined for CPI. The $T_{d}$ was determined to ensure that the heating temperature range used in the rheological analysis was sufficient to denature (a necessary step in the gelation process) the protein. The thermogelation properties of $\mathrm{CPI}$ in a mixed system with $\kappa$-carrageenan ( $\kappa$-CAR) or guar gum were examined using dynamic rheological testing. Rheological data (Table 1) showed a synergistic interaction between CPI and $\kappa$-CAR which produced stronger gels with elastic structure $\left(\mathrm{G}^{\prime}=\right.$ 97465).

Ionic interaction (under suitable conditions of $\mathrm{pH}$ and ionic strength) is one form of non-specific interactions between proteins and polysaccharides. At $\mathrm{pH}$ values below the protein isoelectric point (IEP), the protein and anionic polysaccharide carry net opposite charges. In this $\mathrm{pH}$ region, insoluble complexes can be formed provided the ionic strength is below 0.1-0.2 [11, 68]. Uruakpa [5] established that when CPI (IEP $=7.0)$ was mixed with $\kappa-\mathrm{CAR}$ at $\mathrm{pH} 6$ and low ionic strength, an insoluble electrostatic complex was formed. Although, mixing CPI and guar gum at $\mathrm{pH} 10$ produced a strong gel $\left(\mathrm{G}^{\prime}=56,440\right)$, its $\mathrm{G}^{\prime}$ (storage modulus; a measure of the number of interactions) value was lower than that of CPI alone $\left(\mathrm{G}^{\prime}=68,795\right)$. It is possible that guar gum interfered with the gelling ability of CPI, suggesting incompatibility. The gel strength (Table 1) of CPI-hydrocolloid mixture was higher under complexing (pH 6) than under incompatibility ( $\mathrm{pH} \mathrm{10).}$ The lower $\mathrm{G}^{\prime}$ value obtained for CPI-guar gum gel may be due to electrostatic repulsion between CPI and guar gum at $\mathrm{pH} 10$. The use of isolated food macromolecular components to provide specific functional properties to a wide range of formulated foods is on the increase in food industries. These food ingredients can contain denatured, aggregated, or hydrolyzed biopolymers; therefore, incompatibility and phase behavior of macromolecular mixtures is of practical importance. Incompatibility of biopolymers, self-association and inter-biopolymer complexing 
Table 1 Gelation properties of canola protein isolate (CPI) in the presence and absence of $\kappa$-carrageenan or guar gum (0.05 M $\mathrm{NaCl} ; 3 \%$, w/v א-carrageenan or $1.5 \%$, w/v guar gum).

\begin{tabular}{|c|c|c|c|c|}
\hline \multirow{2}{*}{ Properties } & \multirow{2}{*}{ CPI (pH 6) } & \multirow{2}{*}{ CPI (pH 10) } & СPI-к-CAR & CPI-guar gum \\
\hline & & & Complexing (pH 6) & Incompatibility ( $\mathrm{pH} 10)$ \\
\hline $\mathrm{G}^{\prime *(\mathrm{~Pa})}$ & $27,755 \pm 757$ & $68,795 \pm 1,082$ & $97,465 \pm 2,454$ & $56,440 \pm 2,051$ \\
\hline $\operatorname{Tan} \delta^{*}$ & $0.19 \pm 0.002$ & $0.14 \pm 0.002$ & $0.15 \pm 0.005$ & $0.18 \pm 0.004$ \\
\hline
\end{tabular}

*Mean \pm SD. G' (storage modulus) indicates number of interactions in a gel network; Tan $\delta$ refers to the type of gel structure.

Source: Uruakpa [5].

contribute to synergistic and antagonistic effects of food formulations [59]. The improved gel characteristics observed [5] in CPI-א-CAR and CPI-guar gum systems were attributed to the complexing and incompatibility phenomenon, respectively (Table 1).

\section{Conclusions and Practical Significance of Protein-Polysaccharide Interactions}

Proteins and polysaccharides interact non-specifically and can create junctions which are mainly due to noncovalent interactions. A better understanding of the interactions between biopolymers will enhance the manipulation of food quality (e.g., sensory properties) by adjusting the interaction in a desirable way. For example, food products with novel structures can be produced by allowing a mixed food system to partially phase separate. Protein-polysaccharide interactions, such as complexing and incompatibility, can be used to lower processing costs and overall product cost. For instance, given that proteins are more expensive than polysaccharides, using proteins in combination with polysaccharides will lower the amount of proteins required in a food system. Thus, a reduced cost of protein can be achieved by the addition of right amount of polysaccharide. In turn, this will lower the overall processing cost. In the study on commercial CPI-hydrocolloid systems, CPI- $\kappa$-carrageenan complexing and CPI-guar gum incompatibility produced gels and emulsions with improved properties. Protein-polysaccharide interactions give a realistic indication of plant protein properties in food systems and provide useful information for the development of functional protein products. In a food system containing proteins, polysaccharides and other components, the interactions between various constituents need to be well balanced so that a stable system evolves.

\section{References}

[1] D.A. Ledward, Protein-polysaccharide interactions, in: J.M.V. Blanshard, R.R. Mitchell (Eds.), Polysaccharides in Food, Butterworths, London, 1979, pp. 205-217.

[2] G. Stainsby, Proteinaceous gelling systems and their complexes with polysaccharides, Food Chemistry 6 (1980) 3-14.

[3] V.B. Tolstoguzov, Some physicochemical aspects of protein processing in foods: Multicomponent gels, Food Hydrocolloids 9 (1995) 317-332.

[4] V.B. Tolstoguzov, Functional properties of food proteins and role of protein-polysaccharide interaction, Food Hydrocolloids 4 (1991) 429-468.

[5] F.O. Uruakpa, Evaluation of canola protein functionality in mixed food systems, Ph.D. Thesis, University of Manitoba, Winnipeg, Manitoba, 2004, p. 282, DAI \# NQ97312.

[6] S.D. Arntfield, R. Cai, Protein-polysaccharide interactions during network formation, in: D.J. Sessa, J.L. Willett (Eds.), Observations Involving Canola Protein: Paradigm for Successful Utilization of Renewable Resources, American Oil Chemists' Society, Champaign, 1998, pp. 108-122.

[7] S.D. Arntfield, Thermal gelation of globular proteins, Current Topics in Peptide Protein Research 1 (1994) 261-273.

[8] M.I. Rubino, S.D. Arntfield, C.A. Nadon, A. Bernatsky, Phenolic protein interactions in relation to the gelation properties of canola protein, Food Research International 29 (1996) 653-659.

[9] J.M. Aguilera, Gelation of whey proteins, Food Technology 49 (1995) 83-89. 
[10] S.D. Arntfield, E.D. Murray, M.A.H. Ismond, Role of disulfide bonds in determining the rheological and microstructural properties of heat-induced protein networks from ovalbumin and vicilin, Journal of Agriculture and Food Chemistry 39 (1991) 1378-1385.

[11] V.B. Tolstoguzov, Functional properties of protein-polysaccharide mixtures, in: J.R. Mitchell, D.A. Ledward (Eds.), Functional Properties of Food Macromolecules, Elsevier Applied Science Publishers, London, 1986, pp. 385-415.

[12] S. Bourriot, C. Garnier, J.L. Doublier, Phase separation, rheology and microstructure of micellar casein-guar gum mixtures, Food Hydrocolloids 13 (1999) 43-49.

[13] V.B. Tolstoguzov, Protein-polysaccharide interactions, in: S. Damodaran, A. Paraf (Eds.), Food Proteins and Their Applications, Marcel Dekker, New York, 1997, pp. 171-198.

[14] A.H. Clark, Gelation of globular proteins, in: S.E. Hill, D.A. Ledward, J.R. Mitchell (Eds.), Functional Properties of Macromolecules, 2nd ed., Aspen Publishers, Gaithersburg, 1998, pp. 77-142.

[15] E. Dickinson, Stability and rheological implications of electrostatic milk protein-polysaccharide interactions, Trends Food Science \& Technology 9 (1998) 347-354.

[16] A.M. Hermansson, Aggregation and denaturation involved in gel formation, in: A. Pour-El (Ed.), Functionality and Protein Structure, ACS Symposium Series 92, American Chemical Society, Washington, DC, 1979, pp. 81-102.

[17] S. Damodaran, Amino acids, peptides and proteins, in: O.R. Fennema (Ed.), Food Chemistry, 3rd ed., Marcel Dekker, New York, 1996, pp. 321-429.

[18] K. Katsuta, M. Hatakeyama, J. Hiraki, Isothermal gelation of proteins: 1. Urea-induced gelation of whey proteins and their gelling mechanism, Food Hydrocolloids 11 (1997) 367-372.

[19] S. Ikeda, E.A. Foegeding, C.C. Hardin, Phospholipid/fatty acid-induced secondary structural change in $\beta$-lactoglobulin during heat-induced, Journal of Agriculture \& Food Chemistry 48 (2000) 605-610.

[20] T. Hosseininia, A.A. Ismail, S. Kubow, Pressure-induced conformational changes of $\beta$-lactoglobulin by variable-pressure Fourier transform infrared spectroscopy, Journal of Agriculture \& Food Chemistry 47 (1999) 4537-4542.

[21] S. Funtenberger, E. Dumay, J.C. Cheftel, High pressure promotes $\beta$-lactoglobulin aggregation through $\mathrm{SH} / \mathrm{S}-\mathrm{S}$ interchange reactions, Journal of Agriculture \& Food Chemistry 45 (1997) 912-921.

[22] J. Ote, E. Schumacher, R. Ipsen, Z.Y. Ju, K.B. Qvist, Protease-induced gelation of unheated and heated whey proteins: Effects of $\mathrm{pH}$, temperature and concentration of proteins, enzyme and salts, International Dairy Journal 9 (1999) 801-812.

[23] E. Dickinson, Enzymic crosslinking as a tool for food colloid rheology control and interfacial stabilization. Trends Food Science \& Technology 8 (1997) 334-339.

[24] O.R. Fennema, Food Chemistry, 3rd ed., Marcel Dekker Inc., New York, 1996, pp. 10-21.

[25] N. Catsimpoolas, E.W. Meyer, Gelation phenomena of soybean globulins: Protein-protein interactions, Cereal Chemistry 47 (1970) 559-570.

[26] J.E. Kinsella, Functional properties of proteins in foods: A survey, in: CRC Critical Reviews in Food Technology, CRC Press, Cleveland, 1976, pp. 219-280.

[27] J.D. Ferry, Protein gels, Advances in Protein Chemistry 4 (1948) 1-78.

[28] P.M. Gilsenan, S.B. Ross-Murphy, Viscoelasticity of thermoreversible gelatin gels from mammalian and piscine collagens, Journal of Rheology 44 (2000) 871-883.

[29] A.H. Clark, C.D. Lee-Tuffnell, Gelation of globular proteins, in: J.R. Mitchell, P.A. Ledward (Eds.), Functional Properties of Food Macromolecules, Elsevier Applied Science Publishers, New York, 1986, pp. 203-272.

[30] A.H. Clark, Biopolymer gels, Current Opinion in Colloidal Interface Science 1 (1996) 712-717.

[31] S.B. Ross-Murphy, Reversible and irreversible biopolymer gels structure and mechanical properties, Physical Chemistry Chemical Physics 102 (1998) 1534-1539

[32] P. Relkin, Reversibility of heat-induced conformational changes and surface exposed hydrophobic clusters of ß-lactoglobulin: Their role in heat-induced sol-gel state transition, International Journal of Biological Macromolecules 22 (1998) 59-66.

[33] X.L. Qi, C. Holt, D. McNulty, D.T. Clarke, S. Brownlow, G.R. Jones, Effect of temperature on the secondary structure of $\beta$-lactoglobulin at $\mathrm{pH} 6.7$ as determined by $\mathrm{CD}$ and IR spectroscopy: A test of the molten globule hypothesis, Biochemistry Journal 324 (1997) 341-346.

[34] J. Belloque, G.M. Smith, Thermal denaturation of $\beta$-lactoglobulin. A ${ }^{1} \mathrm{H}$ NMR study, Journal of Agriculture \& Food Chemistry 46 (1998) 1805-1813.

[35] M. Bouraoui, S. Nakai, E. Li-Chan, In situ investigation of protein structure in Pacific whiting surimi and gels using Raman spectroscopy, Food Research International 30 (1997) 65-72.

[36] K. Nakamura, M. Kiriyama, A. Takada, H. Maeda, N. Nemoto, Structure and dynamics of ovalbumin gels III, solvent effect, Rheologica Acta 36 (1997) 252-261.

[37] C. Eloffson, P. Dejmek, M. Paulson, H. Burling, Atomic force microscopy studies on whey proteins, International Dairy Journal 7 (1997) 813-819.

[38] L.G. Phillips, D.M. Whitehead, J. Kinsella, 
Structure-Function Properties of Food Proteins, Academic Press, San Diego, CA, 1994, pp. 153-169.

[39] R.L. Whistler, J.N. BeMiller, Carbohydrate Chemistry for Food Scientists, American Association of Cereal Chemists, St. Paul, 1997, pp. 187-194.

[40] I.C.M. Dea, Polysaccharide conformation in solution and gels, in: D.R. Lineback, G.E. Inglett (Eds.), Food Carbohydrates, AVI Publishing Company, Inc., Westport, 1982.

[41] D. Oakenfull, Gelling agents, CRC Critical Review Food Sciience \& Nutrition 26 (1987) 1-25.

[42] M. Glicksman, Food applications of gums, in: D.R. Lineback, G.E. Inglett (Eds.), Food Carbohydrates, AVI Publishing Company, Inc., Westport, 1982, pp. 125-133.

[43] D. Eagland, Nucleic acids, peptides and proteins, in: F. Franks (Ed.), Water: A Comprehensive Treatise, Plenum Press 4 (1975) 305-309.

[44] L.W. Léger, S.D. Arntfield, Thermal gelation of the $12 \mathrm{~S}$ canola globulin, Journal of the American Oil Chemists Society 70 (1993) 853-861.

[45] S.D. Arntfield, E.D. Murray, M.A.H. Ismond, Influence of protein charge on the microstructural and rheological properties of heat-induced networks from ovalbumin and vicilin, Journal of Texture Studies 21 (1990b) 295-322.

[46] V.J. Savoie, S.D. Arntfield, Effect of $\mathrm{pH}$ and cations on the thermally induced gelation of ovalbumin, Journal of Texture Studies 27 (1996) 286-306.

[47] S.D. Arntfield, E.D. Murray, M.A.H. Ismond, Influence of salts on the micro-structural and rheological properties of heat-induced protein networks from ovalbumin and vicilin, Journal of Agriculture \& Food Chemistry 38 (1990a) 1335-1343.

[48] T.A. Gill, M.A. Tung, Thermally induced gelation of the $12 \mathrm{~S}$ rapeseed glycoprotein, Journal of Food Science 43 (1978) 1481-1485.

[49] D.J. McClements, Non-covalent interactions between proteins and polysaccharides, Biotechnology Advances 24 (2006) 621-625.

[50] S.D. Arntfield, A. Bernatsky, Characteristics of heat-induced networks for mixtures of ovalbumin, Journal of Agriculture \& Food Chemistry 41 (1993) 2291-2295.

[51] E. Dickinson, Interfacial structure and stability of food emulsions as affected by protein-polysaccharide interactions, Soft Matter 4 (2008) 932-942

[52] J. Lee, Physical properties of polysaccharides and their interactions with protein at multi-length scales, Ph.D. Thesis, The State University of New Jersey, 2008, p. 169.

[53] R.M. Musampa, M.M. Alves, J.M. Maia, Phase separation rheology and microstructure of pea protein-k-carrageenan mixtures, Food Hyrocolloids 21 (2007) 92-99.
[54] M.C. Nunes, A. Raymundo, I. Sousa, Rheological behavior and microstructure of pea protein- $\kappa$-carrageeenan-starch gels with different setting conditions, Food Hydrocolloids 20 (2006) 106-113.

[55] E. Dickinson, Use of nanoparticles and microparticles in the formation and stabilization of food emulsions, Trends in Food Science and Technology, 2011, http://dx.doi.org/10.1016/j.tifs.2011.09.006.

[56] V.B. Tolstoguzov, Functional properties of protein-polysaccharide mixtures, in: S.E. Hill, J.R. Mitchell, D.A. Ledward (Eds.), Functional Properties of Food Macromolecules, 2nd ed., Aspen Publishers Inc., Gaithersburg, 1998, pp. 642-667.

[57] S.K. Samant, R.S. Singhal, P.R. Kulkarni, D.V. Rege, Protein-polysaccharide interactions: A new approach in food formulations, International Journal of Food Science \& Technology 28 (1993) 547-562.

[58] D.A. Ledward, Protein-polysaccharide interactions, in: N.S. Hettiarachy, G.R. Ziegler (Eds.), Protein Functionality in Food Systems, Marcel Dekker, New York, 1994, pp. 225-257.

[59] V.B. Tolstoguzov, Some thermodynamic considerations in food formulation, Food Hydrocolloids 17 (2003) 1-23.

[60] S.M. McCurdy, Effects of processing on the functional properties of canola/rapeseed protein, Journal of the American Oil Chemists Society 67 (1990) 281-284.

[61] FAO, Protein Quality Evaluation, Report of Joint FAO/WHO Expert Consultation, Food and Agriculture Organization of the United Nations, Rome, 1992.

[62] D.M. Klockeman, R. Toledo, K.A. Sims, Isolation and characterization of defatted canola meal protein, Journal of Agriculture \& Food Chemistry 45 (1997) 3867-3870.

[63] M.A.H. Ismond, W.L. Welsh, Application of new methodology to canola protein isolation, Food Chemistry 45 (1992) 125-127.

[64] F. Shahidi, North American production of canola, in: F. Shahidi (Ed.), Canola and Rapeseed: Production, Chemistry, Nutrition and Processing Technology, AVI-Van Nostrand Reinhold, New York, 1990, pp. 1-10.

[65] F.W. Sosulski, Rapeseed protein for food use, Developments in Food Proteins 2 (1983) 109-132.

[66] J.D. Jones, Rapeseed protein concentrate preparation and evaluation, Journal of the American Oil Chemists Society 56 (1979) 716-721.

[67] K.D. Schwenke, R. Mothes, K. Marzilger, J. Borowska, H. Kozlowska, Rapeseed protein polyanion interaction-Turbidimetric studies in systems with phosphate-containing polyanions, phytic acid and octometaphosphate, Die Nahrung 31 (1987) 1001-1013.

[68] J.L. Doublier, C. Garnier, D. Renard, C. Sanchez, Protein-polysaccaharide interactions, Current Opinions in Colloids \& Interface Science 5 (2000) 202-214. 